\title{
THE CARE AND FEEDING OF ADULTS WITH DOUBTS ABOUT CHILDREN.
}

\author{
By Logan Clendening.
}

John Bale Sons \& Danielsson, Ltd., 83-91, Great Titchfield Street, W.1. Price 6/-.

In these days of newspaper medicine, societies and faddists, all preaching how much food we should take, the number of calories that should be consumed, the amount of exercise that should be indulged in-to say nothing of advice and fashions as regards alcohol, the bringing up of children and the like- it is perhaps refreshing to find a doctor, out of his own experience (which is obviously considerable) writing a book maintaining that the old ways were best. The author definitely declares himself to be in favour of many of the ideas of the early Victorians and brings considerable evidence, not only from his own experience, but from published writings, to show to what an absurd degree the pendulum has swung to the modern side.

Perhaps the author is most illuminating and certainly most amusing when he is discussing the iniquities of so-called birth control, and perhaps the best criterion of his criticism is the way in which he very nearly proves that such a scheme is in many cases impossible. His views on diet, on weight reducing, on alcohol and exercise appear to the reviewer to be full of common sense. The appearance of this work is timely as a corrective to many fads, fashions and theories which are so prevalent to-day-often preached without any good evidence of their virtue and, in too many cases, wilfully blind to the harm that they cause.

The book is written in a definitely racy style and in places is most amusing and possibly even a little "broad". Nevertheless, there is one chapter with which we thoroughly disagree, and that is the chapter on nurses. Certainly the author's comments on this branch of the profession are unjust and uncalled for, and, if his experience has been such as he hints then we cannot believe that he has met with nurses of the best type. We are sorry to say that this chapter would have been much better omitted, as it spoils a book which shows much careful thought, which is set down in readable fashion, which is entertaining, and which for the most part is full of sound common sense.

\section{MATERNAL MORTALITY AND MORBIDITY}

\author{
By Prof. J. M. Munro Kerr, M.D., F.r.F.P.S.(Glas.), F.C.o.G.
}

Messrs. E. \& S. Livingstone, Edinburgh. 25/- nett.

In his book, Maternal Mortality and Morbidity, Professor J. M. Munro Kerr has assembled information on the problem from all available sources. Following an Introduction, the work is divided into four parts. The first part deals with the causes, sociological factors and statistical evidence receive each a long chapter. There is also a full review of the pathology and bacteriology of puerperal sepsis. The influence of Abortion on Maternal Mortality is considered from its ethical and humanitarian aspects. The importance is demonstrated of the remote effects of Maternal Mortality and subsequent disablement. Part two, entitled Prevention, is concerned with antenatal and intranatal care, and in this respect an inspection of the limited value of ante-natal work deserves especial mention. The third part reviews the maternity services as they exist to-day. The maternity hospitals, the midwife service, and the training of the medical student in Obstetrics are analysed fully. The fourth, and last part, is the author's scheme for a National Maternity Service. This suggested service was outlined in 1931 in the Journal of the Royal Sanitary Institute and 
is based on the assumption that the normal midwifery of the country is passing, and will continue to pass, into the hands of midwives, and that general practitioners for the most part do not wish to retain it.

There is a chapter on neonatal death by Dr. G. B. Fleming, and four appendices. So much for the structure of this remarkable book, whose chief object is to suggest how co-operation between the numerous and different agencies concerned with maternal welfare may be established. The work entailed in the collection of material and care of its arrangement is immense. In this mass of facts, figures, and conjectures Professor Munro Kerr's observations appear few and far between. His comments and suggestions actually are so numerous that it is impossible in this short review to attempt their criticism. Suffice to say he has sorted, moulded, and correlated his information so successfully that, with the possible exception of the chapters that deal with statistics, the whole work is easily read and absorbed. Almost certain it is that never before have so many of the problems of Maternal Morbidity and Mortality been collected and considered in one book. The author deserves the highest praise, and his efforts have established another foundation on which can be based in the future work of a constructive nature. The Index is adequate, and throughout no fact or statement is quoted but that the authority for the same is given in a footnote. Lastly, the type is large and clear and the production of the volume as a whole is extremely well done.

\section{QUALITATIVE ANALYSIS}

By H. S. MOODEY, M.A.

Qualitative analysis is regarded by some people, even by some chemists, as a rather contemptible subject and its pursuit as a waste of time or nearly so. If qualitative analysis is practised merely with the object of identifying a single substance or even a "mixture containing four radicles" by following a rigid set of directions so devised as to lead the student to accomplish this object and no other, then this view of the subject is the only one that can be taken. But if analysis is taught by training the student to make full and correct observations, to draw conclusions from them, to practise the adjustment of his quantities, to realise that the great majority of his reactions are general ones, to make a study of his material, and finally to enter a proper record of his work in his note book, then this subject is a discipline of the greatest value.

Mr. Moodey has written this book to give the student a thorough understanding of the processes involved in his experimental work and he claims, quite justly, that in a large measure the study of physical chemistry can be centred round that of qualitative analysis. So he prefaces his book of 174 pages with a section on the "Theoretical Bases" of analysis extending to 61 pages
William Heinemann. Price, 5/-.

and dealing with such fundamental matters as Mass Action, the Ionisation of Water, the Strength of Acids, Solubility Products and the like. Nor does he omit to point out the abnormality of strong electrolytes, indeed he indicates, necessarily briefly, the lines on which Debye and Huckel are attempting to form a more comprehensive theory of solutions.

In the experimental part of the book all the standard methods of analysis are clearly set out and the reader is never allowed to forget the theory underlying them. As an example it may be mentioned that no less than four methods are given for the separation of the metals of the iron and manganese groups. There are also sections dealing with spectrum analysis and on the use, now becoming so general, of organic reagents for the detection of metals.

The book is admirably suited to the requirements of the advanced student of inorganic chemistry; it is much too difficult for the medical student who has to complete his study of inorganic chemistry and two other subjects in one year. The author is addicted to the use of foot notes; there are more than one hundred of these to divert the reader's attention from the text. 